\title{
The Causal Analysis of Requested Alterations for Pressure Garments
}

\author{
Chia-Fen Chi, Chih-Hsiang Lin, and Hung-Wei Cheng \\ Department of Industrial Management, \\ National Taiwan University of Science and Technology \\ 43 Keelung Road, Section 4, Taipei, Taiwan 106 \\ chris@mail.ntust.edu.tw
}

\begin{abstract}
The purpose of this study was to examine altered pressure garments requested by burn patients, in Taiwan. Three hundred forty-two pressure garments needing alterations were collected from 127 burn patients at the Sunshine Foundation Organization, an nonprofit organization for burn patients to identify the major defects found in these pressure garments and their causes. Causes of required alterations were classified according to a hierarchical coding scheme focusing on poor fit, discomfort, component part, fabric and sewing, and cosmetics to identify systematic problems for each garment type. The result of our analysis indicated that the majority of the pressure garment alterations were related to poor fit in circumferential and longitudinal dimensions of the various body parts, incorrect position and size of openings for eyes, nose, ears, and mouth, or inappropriate length or position of zippers. Information derived from this causal analysis can be applied in helping to reduce the recurrence of alterations in pressure garment, thus improving the quality and effectiveness of pressure therapy.
\end{abstract}

Keywords: pressure garment, defect analysis, causal analysis.

\section{Introduction}

Optimal scar management requires that pressure garments be worn by burn patients for at least 23 hours a day and for at least 9 months to 2 years to provide adequate, consistent and sustained pressure (Cheng, et al., 1996; Williams, Knapp, \& Wallen, 1998). Previously, the majority of researchers on pressure garments have indicated that patients were not satisfied with their garments and therefore were not wearing them long enough (Brown, 2001). Johnson, et al., (1994) found that only $41 \%$ of pressure garment wearers were fully compliant with their treatment. Problems with movement, appearance, fit, comfort, swelling of extremities, rashes and blistering all resulted in a low compliance rate (Macintyre \& Baird, 2006). Interestingly, the clinicians had a different perception from the patients. Stewart, et al. (2000) indicated that clinicians were largely unaware of their patients experiences of excessive skin friction caused by the garments and that not a single clinician believed that the garments were poorly constructed. The clinicians' apparent lack of attention to the effects of poor 
garment construction and fit mitigates against the implementation of simple interventions to improve garment comfort (Stewart, et al, 2000).

Alterations can be done to improve fit and to provide more consistent pressure to a certain scar areas or to help patients to lessen their difficulties in donning garment, maintaining personal hygiene and relieving discomfort (Pratt \& West, 1995). Each alteration takes time and other resources from the garment providers and cause some inconvenience for the client. Fewer alterations required is an important quality for custom-made pressure garments because reliability of fit with the first garment ordered is indicated by $90 \%$ out of 101 burn centers, as one of the key factors used in the selection of a manufacturer (Ward, 1993). Mays, Jones, Holloway, et al., (1990) suggested that the causal analysis of alteration (defect) provide a much better understanding of why an error occurred and how to prevent its reoccurrence. Since there are some reoccurring causes behind these alterations, by identifying alterations and putting them into categories can determine what areas need to be addressed in order to improve the quality and productivity of pressure garments.

You, Wang, Luo, et al. (2002) stated that wearing pressure comfort is one of the most important factors influencing a wearer's sensation of comfort for these tightfitting garments and are basically determined by garment fit, fabric extensibility and garment style. In the current study, factors related to garment fit were singled out to indicate possible deficiency or human errors in patient measurement or other pressure garment making factors. In some cases, problems could also arise from the irregularity of a body shape (eg, patient with a hunch back) or change in body size of burn patients. Our study aims to articulate and differentiate the causes of needed alterations into orthogonal and consistent categories (Chi, Chang, and Ting, 2005; Chi, Yang, and Chen, 2008) because this choice of a classification leaves little room for confusion and the set of causes are sufficient enough to cover the seven major pressure garment making stages and include all alteration cases (Chillarege, Bhandari, Chaar, et al., 1992). Through a systematic collection and analysis of the causes of alteration, we can prevent the recurrence of alterations and reach a consensus concerning the quality of a pressure garment. This study collected and analyzed 342 requested alterations from a local Taiwan workshop to identify the causes of alterations for preventing recurrence and thereby save cost, time, and reduce the inconvenience of the burn patients, who are required to use pressure therapy.

\section{Methods}

\subsection{Data Collection}

This study analyzed 342 alterations and/or repairs requested by 127 clients of the Sunshine Organization between in 2007. For each alteration, the following information was collected: age, gender, garment types, causes of alterations and corrective measures that were completed, to fix any problem. The Sunshine Foundation was founded in 1981 to provide professional recovery services for burn survivors which includes their physical, psychological, and social rehabilitation. Burn patients were referred to the pressure garment workshop of the Sunshine Foundation after being 
treated, diagnosed, and assessed by medical doctors at Taiwan hospital burn centers. A service team composed of 4 occupational therapists, 3 physical therapists, 2 sewing technicians, and 1 general assistant was made available to all burn patients. In 2006, a total of 2633 pressure garments were custom-made for 530 burn patients by the Sunshine Organization. This accounted for more than one-third of the total 1,458 of burn patients in 2006, assuming that all burn patients received pressure therapy.

Table 1. Pressure garment types produced and altered in 2006 and 2007

\begin{tabular}{|c|c|c|c|c|c|c|c|c|}
\hline & & Make & $\begin{array}{l}\text { Alter- } \\
\text { nation }\end{array}$ & $\begin{array}{l}\text { Alternation vs. } \\
\text { Made Ratio }\end{array}$ & Zipper & Hook & Velcro & $\begin{array}{l}\text { Elastic } \\
\text { Belt }\end{array}$ \\
\hline \multirow[t]{10}{*}{2006} & Mask & 143 & 377 & 2.6 & 34 & 0 & 0 & 0 \\
\hline & Collar & 92 & 53 & 0.6 & 0 & 0 & 12 & 0 \\
\hline & Vest & 201 & 488 & 2.4 & 0 & 38 & 0 & 1 \\
\hline & Sleeves & 594 & 1014 & 1.7 & 164 & 0 & 0 & 2 \\
\hline & Gloves & 759 & 1145 & 1.5 & 182 & 0 & 0 & 0 \\
\hline & Pants & 279 & 732 & 2.6 & 73 & 45 & 0 & 0 \\
\hline & Stockings & 125 & 79 & 0.6 & 13 & 0 & 0 & 1 \\
\hline & Foot glove & 435 & 432 & 1.0 & 51 & 0 & 0 & 0 \\
\hline & Finger glove & 5 & 33 & 6.6 & 0 & 0 & 0 & 0 \\
\hline & Total & 2633 & 4353 & 1.65 & 517 & 83 & 12 & 4 \\
\hline \multirow[t]{10}{*}{2007} & Mask & 159 & 452 & 2.8 & 32 & 1 & 0 & 0 \\
\hline & Collar & 72 & 62 & 0.9 & 0 & 0 & 0 & 0 \\
\hline & Vest & 248 & 580 & 2.3 & 0 & 68 & 0 & $17^{*}$ \\
\hline & Sleeves & 753 & 1139 & 1.5 & 154 & 0 & 0 & $33^{*}$ \\
\hline & Gloves & $969 *$ & 1299 & 1.3 & 229 & 0 & 0 & 0 \\
\hline & Pants & $356^{*}$ & 725 & 2.0 & 73 & 71 & 0 & 0 \\
\hline & Stockings & 98 & 66 & 0.7 & 16 & 0 & 0 & $4^{*}$ \\
\hline & Foot glove & 538 & 569 & 1.1 & 49 & 0 & 0 & 0 \\
\hline & Finger glove & 74 & 0 & 0.0 & 0 & 0 & 0 & 0 \\
\hline & Total & 3267 & 4892 & 1.5 & 553 & 140 & 0 & 54 \\
\hline
\end{tabular}

* Significant at 0.05 based on one-tail t statistic.

The design and fabrication of a pressure garment at the Sunshine Foundation followed the seven major stages: (1) patient measurement, (2) selection of garment design, (3) fabric selection, (4) drafting a pattern, (5) cutting a pattern from fabric, (6) sew the garment together, (7) fitting the garment to the patient, as described in Pratt \& West (1995) with some variations to its sequence.

Alteration was at no extra cost for burn patients to ensure compliance. In 2006, about 4,353 alterations were made for various reasons, while only 2633 garments were made during this same period of time (See Table 1). Some garment types required a significant greater number of alterations, such as finger gloves (6.6 alterations), masks (2.6 alterations), pants (2.6 alterations), and vests (2.4 alterations). On an average, each pressure garment required 1.65 alterations. Regarding the 616 alterations which were made on the components, including zippers, hooks, Velcro and the 
elastic belt, the zippers in particular represented $84 \%$ of all components. Before the formal data collection stage, an open-ended descriptive survey was used to collect qualitative description on the causes and corrective measures of 40 alterations. After an extensive review of the collected survey and literature (Williams, Knapp \& Wallen, 1998; Stewart, Bhagwanjee, Mbakaza, et al., 2000; Cheng, Chan, Fong, et al., 1996) and several discussions with the service team at the Sunshine Organization, the causes of garment alterations were categorized into major categories such as problems related to garment fit, garment comfort, component parts, fabric and sewing, and cosmetics. Each category was further divided into a hierarchical list of choices targeting potential improvements in the making of pressure garment and service processes (See Table 2). On the other hand, corrective measures were categorized into garment sewing, component alteration, cut hole or adjust the opening, and alter garment design, each followed by a list of choice as shown in Table 2. Eventually, a data collection form including personal information of the patient, and list of causes for alteration and corrective measures, along with a garment pattern chart was composed. The data collection form was filled out by 3 trained occupational therapists and 1 physical therapist, because burn patients or their caretakers could hardly verbalize these alterations.

\subsection{Statistical Analyses}

All recorded data was classified into useful categories for frequency distribution and other analyses. Cramer's V and Phi coefficient analysis, based on Chi-square, were used to examine the dependency trend between factors (Kurtz, 1999) and levels of factors, respectively. Where expected frequencies were less than 5, Fisher's exact test was used in place of Chi-square (Mehta, Patel, Senchaudhuri, 1992).

\section{Results}

The garment types and design options of 342 alterations were tabulated in Table 2 . The majority of garment alterations were caused by poor fitting, particularly garment that were too loose (144 times), too tight (64 times), or change in body size (22), incorrect position or size of opening (12), too short (11), collar too high (9), too long (7), and garment displacement created by activity (7). It was found that some of these garments became too loose due to a gradual decline in the skin-and-garment interfacial pressure. For those garments that were too loose, too long, and too short cases, seven cases indicated that an error had occurred, especially when measuring gloves (2), pants (2), sleeves (2), and foot gloves (1). Some of these measurement errors were caused by the misreading of the figures. An incorrect garment pattern was indicated in 5 cases including masks ( 3 too loose, 1 too tight), and gloves ( 1 too loose). Other cases included missing the mix-axilla, when taking measurement for a sleeve or the reduction rate was incorrect when drafting the pants. Only about 20 alterations were caused by garment discomfort, such as excessive friction between garment and skin (10), uncomfortably hot to wear (4), difficult for open wound healing (3), difficult to put on or take off or use the toilet (3), and difficult for proper burn wound healing (3). 
Table 2. Information collected on 127 burn patients and 342 garment alterations

\begin{tabular}{|c|c|c|}
\hline Factor & Frequency & Percentage \\
\hline Garment Type Gloves (gauntlet, mitten) & 86 & 25.1 \\
\hline Vest (long-sleeved, short-sleeved, shoulder strap) & 74 & 21.6 \\
\hline Panty and brief & 57 & 16.7 \\
\hline Face mask, head band, chin strap & 50 & 14.6 \\
\hline Sleeve (shoulder flap with sleeve) & 40 & 11.7 \\
\hline Foot glove & 23 & 6.7 \\
\hline Stocking and anklet & 7 & 2.1 \\
\hline Collar & 5 & 1.5 \\
\hline \multicolumn{3}{|l|}{ Causes of Garment Alterations } \\
\hline \multicolumn{3}{|l|}{ Poor fit } \\
\hline Too loose & 144 & 29.8 \\
\hline Too tight & 64 & 18.7 \\
\hline Change in body size & 22 & 6.4 \\
\hline Incorrect position or size of opening & 12 & 3.5 \\
\hline Too short & 11 & 3.2 \\
\hline Neck collar too high & 9 & 2.6 \\
\hline Too long & 7 & 2.0 \\
\hline Garment displacement created by activity & 7 & 2.0 \\
\hline \multicolumn{3}{|l|}{ Discomfort } \\
\hline Excessive friction between garment and skin & 10 & 2.9 \\
\hline Uncomfortably hot to wear & 4 & 1.2 \\
\hline Difficult to put on and take off or use the toilet & 3 & 0.9 \\
\hline Difficult for burn wound healing & 3 & 0.9 \\
\hline \multicolumn{3}{|l|}{ Component part } \\
\hline Poorly positioned component & 9 & 2.6 \\
\hline Defective component & 6 & 1.8 \\
\hline \multicolumn{3}{|l|}{ Fabric and sewing } \\
\hline Tear/hole Wear/friction & 18 & 5.3 \\
\hline Break in the seams & 8 & 2.3 \\
\hline \multicolumn{3}{|l|}{ Cosmetics } \\
\hline Exposed garment & 5 & 1.5 \\
\hline \multicolumn{3}{|l|}{ Corrective measures } \\
\hline \multicolumn{3}{|l|}{ Garment sewing } \\
\hline Reduce circumstances to the problem area & 135 & 39.5 \\
\hline Add circumstances to the problem area & 50 & 14.6 \\
\hline Reduce length & 25 & 7.3 \\
\hline Increase length & 17 & 5.0 \\
\hline Mended holes /breaks in the seams & 26 & 4.9 \\
\hline Adding double layer on a specific area & 5 & 1.5 \\
\hline Insert soft lining over fragile area & 4 & 1.2 \\
\hline Cut open along the seam & 5 & 1.5 \\
\hline \multicolumn{3}{|l|}{ Component alterations } \\
\hline Reposition the component & 29 & 8.5 \\
\hline Insert or add a component & 14 & 4.0 \\
\hline Replace component & 6 & 1.8 \\
\hline Soft pad to fill up the concave area & 6 & 1.8 \\
\hline Cut hole or adjust the size and position of opening & 17 & 5.0 \\
\hline \multicolumn{3}{|l|}{ Alter design } \\
\hline Alter sleeved vest into sleeveless & 3 & 0.9 \\
\hline
\end{tabular}


Association Between Factors And Between Levels of Factors.The Cramer's V coefficients indicate that significant associations exist between garment types and causes for alteration $(\mathrm{V}=0.32, \mathrm{p}<0.01)$ and between causes of alteration and corrective measures $(\mathrm{V}=0.66, \mathrm{p}<0.01)$. Table 3 identified the distinctive cause of alteration for each garment type. Garment too loose (30 cases, $\varphi=0.15$ ) and incorrect in size or the position of the opening ( 8 cases, $\varphi=0.28$ ) were significantly associated with alterations of the mask. These alterations of the mask which was too loose were mainly for the ears (7 cases), chin (7), neck (6), nose (3), and cheek (1). For incorrect sizes or positions of the opening, month (3), eyes (1), ears (1), and nose (1) were the major problem areas. Alteration of the collar was related to the Adam's apple or the fitting of another piece of garment, such as the mask ( 2 cases, $\varphi=0.28$ ).

Alterations for the vest was mainly associated with the collar being too high (7 cases, $\varphi=0.22$ ), uncomfortably hot to wear ( 3 cases, $\varphi=0.14$ ) or exposed garment ( 5 cases, $\varphi=0.23$ ). A machine operator, deliveryman and the mother of an active child reported that pressure garments were uncomfortably hot to wear. Neckline (4 cases) and sleeve (1 case) were examples causing the garment exposure problems and resulting in poor cosmetics.

Glove alterations were significantly associated with garments that were too short (6 cases, $\varphi=0.12$ ), poorly positioned zippers ( 5 cases, $\varphi=0.12$ ) and a break in the seam ( 6 cases, $\varphi=0.18$ ). Six clients whose garments were too short indicated that their gloves were too short in the little (2) and ring fingers (1), or they developed contracture and deformity in their knuckle (2), or it was not long enough to cover the scar on the back of their hand close to the wrist (1). These poorly positioned zippers were all caused by zippers being placed too close to the scar and resulted in pain and discomfort.

Alteration on pants was significantly associated with the difficulty of putting on and taking off of garments or when children wanted to use the toilet (3 cases, $\varphi=0.21$ ). Excessive friction was the cited main cause for the alteration of anklet ( 2 cases, $\varphi=0.22$ ) and complaints were actually about the zippers. Changes in body size was due to children growth process (4 cases), diminished edema ( 2 cases), and weight loss $(1$ case) resulted in the alteration of foot gloves ( 7 cases, $\varphi=0.26$ ). Clients reported sliding loose gloves and tightness of web space within gloves that were too loose or too tight, respectively. For vest garments that were too loose, under the arm pit, at the side of the breast, neckline, or shoulder were the major problem areas while arm pits, arms, shoulders, the stomach, and sleeve cuffs were related to vests that were too tight. Similarly, stomach, waist, buttock, calf, and lower leg problems were the major areas for both too tight and too loose fitting pants.

\section{Discussion}

This study developed a classification system in which to categorize the causes for alterations and to determine what areas need to be addressed for improving the quality of these garment. The result of our analysis indicated that the majority of pressure garment alterations were related to poor fitting in circumferential and longitudinal dimensions for various body parts. Therefore, it can be expected, that the fit affects the comfort and the wear life of a garment (Brown \& Rice, 1988), and the fit is 
determined by pattern making and pattern making begins with the body measurements (Hudson, 1980). Fit is even more difficult to be achieved since in pressure garments, fit means applying sufficient pressure by fabric to have certain curative effects for each treatment stage $(\mathrm{Ng}, 1994)$. This finding leads us to look into the process of taking measurements of burn patients. In order to obtain detailed and correct measurements from the burn patients, a typical cycle for measuring garments includes burn scar assessment, selection of garment design, posture positioning, identification of landmarks, taking measurements, recording and checking measurements.

All occupational therapists and physical therapists at the Sunshine Foundation were required to have 36 hours of training regarding human body measurements including: human anatomy, garment fabrication, fabric design and analysis, measurement tools, and measurement skills. However, it was found that measurement errors cannot be fully prevented due to a number of factors which include subject positioning, imprecision in landmark location, and instrument applications (Meunier \& Yin, 2000) which will be elaborated upon as follows.Some pressure garment manufacturers such

Table 3. Significant association between cause of alterations and garment types

\begin{tabular}{|c|c|c|c|c|c|c|c|c|}
\hline & Mask & Collar & Vest & Gloves & Pants & $\begin{array}{l}\text { Ank- } \\
\text { let }\end{array}$ & Foot glove & Sleeves \\
\hline $\begin{array}{l}\text { Garment } \\
\text { too loose }\end{array}$ & $\begin{array}{c}30 \\
0.15^{++}\end{array}$ & $\begin{array}{c}2 \\
\mathrm{f}-0.01\end{array}$ & $\begin{array}{c}22 \\
-0.13^{*}\end{array}$ & $\begin{array}{c}33 \\
-0.04\end{array}$ & $\begin{array}{c}24 \\
0.00\end{array}$ & $\begin{array}{c}4 \\
\mathrm{f} 0.04\end{array}$ & $\begin{array}{c}10 \\
0.01\end{array}$ & $\begin{array}{c}19 \\
0.04\end{array}$ \\
\hline $\begin{array}{l}\text { Incorrect position } \\
\text { of opening }\end{array}$ & $\begin{array}{c}8 \\
\mathrm{f} 0.28^{++}\end{array}$ & 0 & $\begin{array}{c}1 \\
\text { f }-0.06\end{array}$ & 0 & $\begin{array}{c}3 \\
{ }^{\mathrm{f}} 0.04\end{array}$ & 0 & 0 & 0 \\
\hline $\begin{array}{l}\text { Neck collar too } \\
\text { high }\end{array}$ & 0 & $\begin{array}{c}2 \\
{ }^{\mathrm{f}} 0.28^{++}\end{array}$ & $\begin{array}{c}7 \\
\mathrm{f} 0.22^{++}\end{array}$ & 0 & 0 & 0 & 0 & 0 \\
\hline $\begin{array}{l}\text { Uncomfortably } \\
\text { hot to wear }\end{array}$ & 0 & 0 & $\begin{array}{c}3 \\
\mathrm{f} 0.14^{+}\end{array}$ & 0 & $\begin{array}{c}1 \\
{ }^{\mathrm{f}} 0.02\end{array}$ & 0 & 0 & 0 \\
\hline $\begin{array}{l}\text { Expose gar- } \\
\text { ment }\end{array}$ & 0 & 0 & $\begin{array}{c}5 \\
{ }^{\mathrm{f}} 0.23^{++}\end{array}$ & 0 & 0 & 0 & 0 & 0 \\
\hline $\begin{array}{l}\text { Garment too } \\
\text { short }\end{array}$ & $\begin{array}{c}1 \\
\mathrm{f}-0.03\end{array}$ & 0 & 0 & $\begin{array}{c}6 \\
{ }^{\mathrm{f}} 0.12^{+}\end{array}$ & 0 & 0 & $\begin{array}{c}1 \\
{ }^{\mathrm{f}} 0.02\end{array}$ & $\begin{array}{c}3 \\
{ }^{\mathrm{f}} 0.09\end{array}$ \\
\hline $\begin{array}{l}\text { Poorly positioned } \\
\text { component }\end{array}$ & 0 & $\begin{array}{c}1 \\
{ }^{\mathrm{f}} 0.13\end{array}$ & $\begin{array}{c}3 \\
{ }^{\mathrm{f}} 0.05\end{array}$ & $\begin{array}{c}5 \\
{ }^{\mathrm{f}} 0.12^{+}\end{array}$ & 0 & 0 & 0 & 0 \\
\hline $\begin{array}{l}\text { Break } \\
\text { in the seams }\end{array}$ & 0 & 0 & $\begin{array}{c}2 \\
{ }^{\mathrm{f}} 0.01\end{array}$ & $\begin{array}{c}6 \\
\text { f } 0.18^{++}\end{array}$ & 0 & 0 & 0 & 0 \\
\hline $\begin{array}{l}\text { Difficult to put } \\
\text { on and take off }\end{array}$ & 0 & 0 & 0 & 0 & $\begin{array}{c}3 \\
{ }^{\mathrm{f}} 0.21^{+}\end{array}$ & 0 & 0 & 0 \\
\hline $\begin{array}{l}\text { Excessive fric- } \\
\text { tion against skin }\end{array}$ & 0 & 0 & $\begin{array}{c}4 \\
\mathrm{f} 0.08\end{array}$ & $\begin{array}{c}3 \\
{ }^{\mathrm{f}} 0.02\end{array}$ & 0 & $\begin{array}{c}2 \\
{ }^{\mathrm{f}} 0.22^{+}\end{array}$ & $\begin{array}{c}1 \\
\mathrm{f} 0.02\end{array}$ & 0 \\
\hline $\begin{array}{l}\text { Change in body } \\
\text { size }\end{array}$ & $\begin{array}{c}2 \\
\mathrm{f}-0.04\end{array}$ & 0 & $\begin{array}{c}4 \\
\mathrm{f}-0.02\end{array}$ & $\begin{array}{c}4 \\
-0.04\end{array}$ & $\begin{array}{c}1 \\
\mathrm{f}-0.09\end{array}$ & 0 & $\begin{array}{c}7 \\
\mathrm{f} 0.26^{++}\end{array}$ & $\begin{array}{c}4 \\
{ }^{\mathrm{f}} 0.05\end{array}$ \\
\hline
\end{tabular}

In each cell, the three numbers give number of cases, the Cramer $\mathrm{V}$ value and significance level, respectively. Only cause with significant $\varphi$ coefficients are listed.

$++: \varphi$ value is positive and significant at $0.01 . ;+: \varphi$ value is positive and significant at 0.05 .

$* *: \varphi$ value is negative and significant at $0.01 . ; *: \varphi$ value is negative and significant at 0.05 .

$\mathrm{f}$ :Fisher's exact test is used instead of $\varphi$. 
as Bio-Concepts Inc. provided instructions on the correct body posture for measurement taking procedures including each body part. However, some burn patients in our study had difficulty maintaining the suggested posture for being measured. Also, the postural differences and breathing movement generate greater variability for waist and chest circumferences (Meunier \& Yin, 2000) and caused measurement errors for pants and vests, respectively. Landmarks are placed on the body to assist with accurate measurements. The measurement reliability on female subjects was poorer than for those of males due to the difference in the amount and pattern of adiposity. Female bony landmarks are generally less developed than in males and thus more difficult to palpate (Bennett \& Osborne, 1986). In our study, burn patients with body parts covered by fat tissue were found to have greater difficulties for obtaining reliable body measurements.

Regarding instrument applications, most measurements are taken with tapes and typically based on feel-by-hand, such as "use retractable tape to take circumference measurements and tighten the tape until it is snug but not snug enough to wrinkle the skin (Bio-Concepts Inc., 2003). In general, a portable 3-D computer graphics system is more accurate and consistent for taking body measurement, but the advantage are not outweighed due to its cost, to justify its practical use for collecting anthropometric data from burn patients. Regarding alterations pertaining to component or optional features, zippers seemed to be the major concern, since both the position and length of zipper are critical and can cause fitting or excessive friction problems because they are stiffer than the rest of the garment. After extensive discussion with members of the Sunshine Foundation workshop and one of the zipper manufacturers, problems associated with zippers can be roughly divided into: (1) the derailment of zipper or teeth, (2) inappropriate position or length of the zipper, and (3) the poor stitching quality of the zipper. Each may require additional data collection and analysis on garments with defective zippers to look for root causes and strategy for improvement.

Concerning the incorrect position and size of openings, eyes, nose, ears, and the mouth seemed to be the most difficult parts. Current work practice at the Sunshine Foundation is to mark opening positions on finished masks fitted directly on the client, then cutting the opening according to the marks on the garment to reduce errors. This work practice had shown to improve the problems with openings. The analysis regarding causes for alterations for pressure garments only stands as an initial step for a complete defect prevention program. Numerous changes had occurred because of the causal data of alterations collected by the occupational therapists and a physical therapist who designed and made the pressure garments. As a result of this defect analysis, the charts of eight major garment types initially designed to mark and collect the cause and location of the alterations had been developed into measurement charts for taking measurements. Figure 1 presents the measurement chart for the mask before and after the defect analysis was conducted. Besides, because of this defect analysis, service team members can learn from their mistakes and become aware of the quality status of their garments. Defect data on the pressure garments was collected between March and September in 2007. Data included monthly total made, alterations, alteration vs. made ratio, number of alterations on zipper, hooks, Velcro and elastic belts in 2007 was compared with those in 2006 to see if there was any significant change during and after the defect analysis had been conducted. From the paired t test statistics, it was found that the sleeves, gloves, and pants had a significant greater number of total made while 
mask and foot gloves had a significant greater number of total alterations, in 2007. Although no significant difference was found in the alteration vs. made ratio, the overall ratio had been reduced from 1.65 to 1.50 . Alterations on finger gloves were eliminated since it was more feasible to construct new finger gloves. In the long run, since each of these causes can be directly related to the seven steps of garment making process for improving the design and manufacturing process, standardized operating procedure could be developed and modified gradually from findings of the causal analysis.

\begin{tabular}{|c|c|c|c|c|c|}
\hline $\begin{array}{c}\text { Landmark } \\
\text { position }\end{array}$ & $\begin{array}{c}\text { Size in inch- } \\
\text { es or cm }\end{array}$ & $\begin{array}{c}\text { Landmark } \\
\text { position }\end{array}$ & $\begin{array}{c}\text { Size in inch- } \\
\text { es or cm }\end{array}$ & $\begin{array}{c}\text { Landmark } \\
\text { position }\end{array}$ & $\begin{array}{c}\text { Size in inch- } \\
\text { es or cm }\end{array}$ \\
\hline $\mathrm{a} \sim \mathrm{b}$ & & $\mathrm{f} \sim \mathrm{g}$ & & $\mathrm{f} \sim \mathrm{d}$ & \\
\hline $\mathrm{b} \sim \mathrm{c}$ & & $\mathrm{g} \sim \mathrm{h}$ & & $\mathrm{g} \sim \mathrm{c}$ & \\
\hline $\mathrm{c} \sim \mathrm{d}$ & & $\mathrm{h} \sim \mathrm{i}$ & & $\mathrm{h} \sim \mathrm{b}$ & \\
\hline $\mathrm{d} \sim \mathrm{e}$ & & $\mathrm{i} \sim \mathrm{j}$ & & $\mathrm{j} \sim \mathrm{b}$ & \\
\hline $\mathrm{e} \sim \mathrm{f}$ & & $\mathrm{j} \sim \mathrm{k}$ & & $\mathrm{k} \sim \mathrm{a}$ & \\
\hline$\ell$ & & $\mathrm{c} \sim \mathrm{m}$ & & $\begin{array}{c}\text { Desired } \\
\text { pressure }\end{array}$ & \\
\hline & & $\mathrm{m} \sim \mathrm{n}$ & & & \\
\hline
\end{tabular}

Fig. 1. The mask measurement chart showing a before and after defect analysis

\section{Conclusion}

Three-hundred-and-forty-two alterations requested by 127 clients of the Sunshine Organization were collected and analyzed for the current study. A categorization system was developed to facilitate the coding and analysis of causes and corrective measures on pressure garment alterations for the improvement of the design, selection of fabric material, and workmanship for the making a pressure garment. The current study developed a systematic classification scheme for the causal analysis of identifiable causes regarding pressure garments produced by a Taiwan custom-made pressure garment workshop. This classification scheme and the analytical approach can be applied to the analysis of other custom-made or ready-to-wear pressure garment manufacturers.

\section{References}

1. Bennett, K.A., Osborne, R.H.: Interobserver measurement in anthropometry. Human Biology 58(5), 751-759 (1986)

2. Bio-Concepts Inc., Measuring for custom-made pressure garments. Bio-Concepts Inc., Phoenix (2003)

3. Brown, C.A.: A comparison of the outcomes of two clinical audits of burn pressure garment satisfaction and compliance in Saudi Arabia. Burns 27, 342-348 (2001)

4. Brown, P., Rice, J.: Ready-to-wear apparel analysis, 2nd edn. Prentice-Hall, Upper Saddle River (1998) 
5. Cheng, S., Chan, A., Fong, S., Lam, M., Leung, A., Lee, P., Tsang, J., Wong, J., Wu, A.: Outcome studies for burn patients in Hong Kong: patients' satisfaction. Burns 22(8), 623626 (1996)

6. Chi, C.-F., Chang, T.-C., Ting, H.-I.: Accident Patterns and Prevention Measures for Fatal Occupational Falls in the Construction Industry. Applied Ergonomics 36, 391-400 (2005)

7. Chi, C.-F., Yang, C.-C., Chen, Z.-L.: In-Depth Accident Analysis of Electrical Fatalities in the Construction Industry. International Journal of Industrial Ergonomics (2008) (in press)

8. Chillarege, R., Bhandari, I.S., Chaar, J.K., Halliday, M.J., Moebus, D.S., Ray, B.K., Wong, M.Y.: Orthogonal defect classification-A concept for in-process measurements. IEEE Transactions on Software Engineering 18(11), 943-955 (1992)

9. Hudson, P.B.: The role of fit and fashion in apparel quality. Bobbin 21(11), 108-122 (1980)

10. Johnson, J., Greenspan, B., Gorga, D., Nagler, W., Goodwin, C.: Compliance with pressure garment use in burn rehabilitation. Journal of Burn Care and Rehabilitation 15, 180 188 (1994)

11. Kroemer, K.H.E.: Engineering Anthropometry. In: Salvendy, G. (ed.) Handbook of Human Factors and Ergonomics. John Wiley \& Sons, New York (1997)

12. Kurtz, N.: Statistical Analysis For The Social Sciences, p. 316. Allyn \& Bacon, MA (1999)

13. Mays, R.G., Jones, C.L., Holloway, G.J., Studinski, D.P.: Experiences with defect prevention. IBM Systems Journal 29(1), 4-32 (1990)

14. Macintyre, L., Baird, M.: Pressure garments for use in the treatment of hypertrophic scars-an evaluation of current construction techniques in NHS hospitals. Burns 31, 11-14 (2005)

15. Macintyre, L., Baird, M.: Pressure garments for use in the treatment of hypertrophic scars-a review of the problems associated with their use. Burns 32, 10-15 (2006)

16. Mehta, C.R., Patel, N.R., Senchaudhuri, P.: Exact stratified linear rank tests for ordered categorical and binary data. J. Computational and Graphical Statistics 1, 21-40 (1992)

17. Meunier, P., Yin, S.: Performance of a 2D image-based anthropometic measurement and clothing sizing system. Applied Ergonomics 31, 445-451 (2000)

18. Ng-Yip, F.: Medical clothing-the stress relaxation and shrinkage of pressure garments. International Journal of Clothing Science and Technology 64, 17-27 (1994)

19. Pratt, J., West, G.: Pressure Garments: A manual on their design and fabrication. Butterworth-Heinemann Ltd., Oxford (1995)

20. Stewart, R., Bhagwanjee, A.M., Mbakaza, Y., Binase, T.: Pressure garment adherent in adult patients with burn injuries: An analysis of patient and clinician perceptions. The American Journal of Occupational Therapy 54(6), 598-606 (2000)

21. Ward, R.S.: Reasons for the selection of burn-scar-support suppliers by burn centers in the United States: a survey. Journal of Burn Care \& Rehabilitation 14(3), 360-367 (1993)

22. Williams, F., Knapp, D., Wallen, M.: Comparison of the characteristics and features of pressure garments used in the management of burn scars. Burns 24, 329-335 (1998)

23. You, F., Wang, J.M., Luo, X.N., Li, Y., Zhang, X.: Garment's pressure sensation (1): subjective assessment and predictability for the sensation. International Journal of Clothing Science and Technology 14(5), 307-316 (2002) 